\title{
DESPLAZAMIENTOS FORZADOS EN EL DESARROLLO DE DESASTRES AMBIENTALES: LA VIOLACIÓN DE LOS DERECHOS HUMANOS COMO REQUISITO PREVIO PARA EL RECONOCIMIENTO DEL REFUGIO AMBIENTAL EN BRASIL
}

\author{
Rubén Miranda Gonçalves ${ }^{1}$ \\ Universidad Internacional de La Rioja (UNIR)
}

Letícia Mirelli Faleiro e Silva ${ }^{2}$

Universidade de Itaúna (UIT)

\section{RESUMEN}

El repentino cambio climático y los desastres ambientales, naturales o provocados por el hombre, han obligado a miles de personas en todo el mundo a abandonar sus países en busca de refugio y de una vida mínimamente digna en otro territorio. Este artículo busca abordar el problema del desplazamiento humano causado por estas catástrofes, investigando la protección legal requerida para estas personas desplazadas a la luz de un análisis del Estatuto de Refugiado desde la perspectiva del principio pro homine. Para ello, además de una explicación sobre el refugiado, como instituto jurídico de protección a nivel mundial, se analizarán los desastres ambientales para discutir, posteriormente, uno de los problemas que surgen, precisamente, por estos desastres, que no es otro que el desplazamiento masivo de personas, forzadas por la falta de condiciones para permanecer en la zona afectada con dignidad. El aspecto metodológico adoptado: jurídico-dogmática; tipo de razonamiento: deductivo; tipos metodológicos de investigación: histórico-jurídico, jurídico-interpretativo, jurídico-prospectivo y jurídico-positivo.

Palabras-clave: desastres ambientales; violación de los derechos humanos; refugio ambiental.

1 Doctor en Derecho, con mención internacional, por la Universidad de Santiago de Compostela (USC). Actualmente es Profesor Contratado Doctor en la Universidad Internacional de La Rioja (UNIR) y director del Máster en Derechos Humanos: Sistemas de Protección. E-mail: ruben. mirandagoncalves@unir.net

2 Doctoranda en Derecho Constitucional en la Universidad de Santiago de Compostela. Máster en Protección de los Derechos Fundamentales por la Universidad de Itaúna. Abogada y Licenciada en Derecho por las Facultades Integradas del Oeste de Minas. Postgraduada en Ciencias Criminales por la Universidad Gama Filho. Postgraduada en Derecho del Trabajo y Procesal del Trabajo por la Facultad Pitágoras. 


\section{FORCED DISPLACEMENTS IN THE DEVELOPMENT OF \\ ENVIRONMENTAL DISASTERS: VIOLATION OF HUMAN \\ RIGHTS AS A PREREQUISITE FOR THE RECOGNITION OF THE \\ ENVIRONMENTAL REFUGE IN BRAZIL}

\section{ABSTRACT}

Sudden climate change and environmental, natural and man-made disasters have forced thousands of people around the world to leave their countries in search of refuge and a minimally dignified life in another territory. This article seeks to address the problem of human displacement caused by these catastrophes by investigating the legal protection required for these displaced persons in the light of an analysis of Refugee Status from the perspective of the pro homine principle. To this end, in addition to an explanation of the refugee, as a legal institute of protection at world level, environmental disasters will be analyzed to discuss, later, one of the problems that arise precisely because of these disasters, which is none other than the massive displacement of people, forced by the lack of conditions to remain in the affected area with dignity. The methodological aspect adopted: juridical-dogmatic; type of reasoning: deductive; methodological types of research: historical-legal, juridical-interpretative, juridical-prospective and juridical-positive.

Keywords: environmental disasters; environmental refuge; violation of human rights. 


\section{INTRODUCCIÓN}

El cambio climático, el crecimiento de la población, el uso irregular de la tierra, el uso desenfrenado de los recursos naturales, la degradación del medio ambiente, la contaminación en sus diversas formas, entre otros factores, han provocado la intensificación y expansión del riesgo de desastres ambientales, ya sean naturales o causados por la acción humana.

Es en este escenario en el que hemos experimentado en los últimos años la ocurrencia de importantes desastres diseminados por todo el mundo, como el tsunami del Océano Índico, que afectó principalmente a Indonesia (2004), el huracán Katrina en Estados Unidos (2005), el terremoto de Caximira en Pakistán (2005), el ciclón en Myanmar (2008), el terremoto en Haití (2010) y las lluvias en la región montañosa de Río de Janeiro (2011). Estos sucesos provocaron la muerte y la destrucción de infraestructuras en las regiones afectadas, lo que provocó que un gran número de personas abandonaran sus "hogares" y salieran en busca de refugio y protección en un lugar seguro.

Debido al acontecimiento de estos eventos y, en consecuencia, al permanecer afectada la infraestructura de un determinado lugar, ya sea de una ciudad, región, parte de un país, la forma de vida de los individuos en este entorno, se ve perjudicada, especialmente en los casos más graves, donde la propia subsistencia queda comprometida. Es prácticamente imposible vivir en la localidad afectada con la mínima dignidad, y por esta razón, en los países más vulnerables, donde la reconstrucción inmediata es difícil, estas personas se ven obligadas a desplazarse internamente dentro de su país, o en casos más graves donde la infraestructura del país en su conjunto se ve afectada, se ven obligadas a cruzar las fronteras en busca de refugio en otro territorio.

Aunque estas personas han abandonado sus países y han cruzado la frontera en busca de refugio en otro territorio, no están legalmente reconocidas como refugiados. Esto ocurre porque el instituto legal del refugio establece dos requisitos indispensables para su reconocimiento. Por lo tanto, además de la persona que cruza la frontera, debe necesariamente estar huyendo de la persecución o temiendo sufrirla.

Los instrumentos mundiales que regulan el refugio, en particular la Convención sobre el Estatuto de los Refugiados de 1951 y su Protocolo de 1967, reconocen como refugiados a las personas que se han visto obligadas a abandonar su país de origen, cruzando sus fronteras en busca 
de protección en un país seguro, porque están siendo perseguidas en su país de origen.

Esos instrumentos son limitados, ya que hay otras innumerables razones por las que miles de personas en todo el mundo abandonan su país y cruzan las fronteras en busca de refugio en otra región. Entre estas razones, destacamos, en el presente artículo, el desplazamiento forzado por la ocurrencia de desastres ambientales o naturales, los cuales, dependiendo de su magnitud, causan una destrucción abrumadora de la infraestructura de la región, lo que sea habitada.

El problema de esta investigación radica en el hecho de que las personas que abandonan un país afectado por una catástrofe ambiental y cruzan la frontera en busca de refugio en otro Estado, no son reconocidas como refugiados por los instrumentos de protección que regulan el instituto legal del refugio. Esto se debe al hecho de que estas personas carecen del requisito de la persecución o de su temor bien fundado. Por esta razón, comienzan a ocupar el limbo jurídico, por así decirlo, sin recibir la protección necesaria.

Es en este contexto que nace una nueva clase de refugiados, llamados "refugiados ambientales", que, a pesar de haber sido desplazados por la fuerza por razones ajenas a su voluntad, reciben una protección atenuada del Estado, sólo porque carecen de un requisito legal para ser reconocidos clásicamente como refugiados.

Este es un problema actual de extrema relevancia, especialmente debido al aumento significativo del riesgo de desastres naturales debido al calentamiento global, que intensifica los eventos climáticos extremos como huracanes, temperaturas extremas, lluvias extremas, derretimiento de glaciares y nieve, y elevación del nivel del mar (CARVALHO, 2015). Además, la relevancia de la investigación también radica en el hecho de que las víctimas de desastres ambientales sufren graves y generalizadas violaciones de los derechos humanos.

Así, en el presente artículo se abordarán los desastres ambientales y luego se discutirá uno de los principales problemas que surgen de estos desastres, a saber, el desplazamiento masivo de personas, forzadas por la falta de condiciones para permanecer en la zona afectada con dignidad.

En este sentido, se hará una explicación sobre el refugiado, tomando como punto de partida su reconocimiento como instituto jurídico de protección a nivel mundial, a través de la Convención sobre el Estatuto de los Refugiados de 1951 y su Protocolo de 1967, así como de los 
instrumentos regionales de protección de este instituto, en particular la Convención de la Organización de la Unidad Africana (OUA) de 1969 y la Declaración de Cartagena de 1984 sobre los Refugiados, que adoptan un concepto ampliado de refugiado.

Finalmente, se presentará el panorama del refugio en Brasil, a través de la Ley 9474/97, para hacer un análisis del concepto de refugio en la ley interna brasileña, a fin de indagar si las personas ambientalmente desplazadas que ingresan a Brasil no pueden ser reconocidas como refugiados tomando en consideración una posible violación de los derechos humanos ante la ocurrencia de desastres ambientales.

Para el desarrollo de la investigación, la metodología utilizada será la investigación bibliográfica, a través de la consulta en doctrinas, textos y artículos científicos, así como la investigación documental basada en la lectura de leyes y juzgadas involucrando al sujeto, a través de un análisis teórico, interpretativo e histórico. El método adoptado será de carácter deductivo.

\section{DESASTRES AMBIENTALES}

Los problemas ambientales que se han producido en todo el mundo, especialmente los de gran magnitud, y que han despertado la preocupación de toda la comunidad internacional son abundantes. Esto se debe a que los tiempos actuales se han caracterizado por la formación de una sociedad postindustrial compleja y productora de riesgos globales, entre los cuales el riesgo ambiental se presenta como una de las especies más relevantes (CARVALHO, 2013). Juárez Freitas apunta que, según todos los indicios, en los próximos millones de años el planeta no se extinguirá, pero la humanidad está en verdadero peligro debido a la gravedad de los problemas actuales (FREITAS, 2016).

El autor Ulrich Beck, por su parte, ve las catástrofes ambientales como el peor tipo de metamorfosis que ha estado ocurriendo en el mundo, mencionando que el cambio climático representa la metamorfosis de la política y la sociedad, y debe ser descubierto y analizado con cautela por la ciencia social del cosmopolitismo metodológico:

Esto no significa que haya una solución fácil al cambio climático. Tampoco significa que los efectos secundarios positivos de los efectos secundarios negativos creen automáticamente un mundo mejor. Y ni siquiera significa que la metamorfosis activa, subpolítica y política sea lo suficientemente rápida como para contrarrestar el 
desenfrenado proceso de catástrofes climáticas que puede arrastrar al mundo entero a sequías, inundaciones, caos, hambrunas y conflictos sangrientos. Sin embargo, la catástrofe también sería una metamorfosis, el peor tipo de metamorfosis (BECK, 2015, p. 65).

En una breve historia, Délton Winter de Carvalho describe las fases de los desastres:

Primero, el desastre fue visto como un fenómeno divino, una manifestación de la furia de los dioses. En un segundo momento, las catástrofes, especialmente las naturales, llegaron a ser percibidas como una demostración de la grandeza y el poder devastador de la naturaleza, contra la cual el hombre podía hacer muy poco. Por último, en la era contemporánea, los desastres, incluso los llamados naturales, se describen como fenómenos que, aunque de alguna manera sean desencadenados por fenómenos naturales, sólo alcanzan la condición de desastres cuando son alimentados por vulnerabilidades (re)producidas socialmente (CARVALHO, 2015, p. 21).

Así, para regular las complicaciones derivadas de un desastre ambiental, la Ley de Desastres surge como una extrema derecha, creada ante la apremiante necesidad de una regulación sensible al riesgo y a la incertidumbre ante la severidad de estos eventos naturales, llamando la atención de la humanidad sobre la crisis ambiental experimentada, especialmente como resultado de un consumo generalizado cada vez más exacerbado, sumado a los efectos de una naturaleza influenciada por el cambio climático (CARVALHO, 2015).

Teniendo en cuenta que, ante un problema, nace una nueva Ley necesaria para regular el caso en cuestión, Délton Winter de Carvalho imparte conferencias:

Hoy en día, el Derecho es uno de los sistemas cuya ambición es dotar de capacidad de decisión en escenarios extremos, dando estabilidad y seguridad jurídica al caos instituido por los desastres. Por otra parte, la profesión jurídica debe llevar a cabo esta tarea de manera suficientemente dinámica, dada la rapidez y urgencia que imponen estos acontecimientos (CARVALHO, 2015, p. 22).

Además, la intervención de la Ley frente a los desastres ambientales es legítima, porque éstos parecen estar más allá de las desgracias aleatorias, como verdaderas y graves consecuencias de las injusticias socioambientales, acumuladas por omisión y descuido (CARVALHO, 2015), e incluso si se denominan eventos naturales, nacen como resultado de vulnerabilidades físicas y sociales, razón por la cual la Ley es responsable de regular las relaciones sociales existentes antes, durante y después de los desastres. 
Sin embargo, los desastres cada vez más comunes e intensos que se han producido en el mundo, suelen presentar en su origen un déficit regulatorio en las normas ambientales. Fruto de ese resultado, las catástrofes se convierten en un trampolín para la evolución del derecho ambiental, al tiempo que son capaces de concienciar a las autoridades y a la opinión pública sobre la necesidad de una mayor regulación y protección del medio ambiente (CARVALHO, 2015).

En este contexto, la Ley de Desastres se ha vuelto cada vez más importante en todo el mundo, tanto como un medio para proporcionar orientación normativa sobre la prevención de la ocurrencia de desastres ambientales, como para dar respuesta a esos eventos, tales como las regulaciones legales de los Estados Unidos y de Europa, que ya cuentan con normas que regulan este tema. En Brasil la regulación de los desastres es todavía incipiente y aparece discretamente en la Ley 12.34/2010, el Decreto 7.257/2010, la Ley 12.608/2012 y la Constitución Federal de 1988.

A pesar de su autonomía, el Derecho de Desastres utiliza las diversas ramas del derecho y sus instrumentos para su propósito específico, que es regular las relaciones de anticipación y respuesta a los desastres. Es aquí donde, bajo la égida de la gestión constante del riesgo, se presentan las funciones estructuradoras del Derecho de Desastres: prevención y mitigación, respuesta a emergencias, compensación y reconstrucción (CARVALHO, 2015).

Además de los problemas típicamente ambientales que rodean a los desastres, los problemas sociales que surgen de ellos son igualmente relevantes:

Por lo tanto, la sensibilidad climática tiende a ejercer una mayor presión con respecto a los llamados desastres "naturales". Sin embargo, también pueden conducir a una mayor desestabilización de las relaciones sociales, intensificando también las posibilidades de un aumento de los desastres antropogénicos. Por lo tanto, la ocurrencia de desastres y su reciente aumento está relacionada con un patrón acumulativo de exposición, vulnerabilidad y ocurrencia de eventos climáticos. En otras palabras, los desastres son el resultado de una combinación de factores físicos y sociales, que dan lugar a eventos de dimensiones suficientemente graves que afectan a vidas humanas, bienes, servicios y recursos ambientales (CARVALHO, 2015, p. $35)$.

Aunque reconocemos la relevancia del sesgo ambiental de los desastres, esta investigación hará un recorte que busca resaltar el contexto social que se deriva de ellos, especialmente el desplazamiento forzado de personas, como se presentará en los siguientes temas. 


\subsection{Refugiados ambientales}

Los desastres ambientales y el cambio climático han dado lugar a un importante flujo de desplazamiento de personas, que migran en busca de un entorno seguro y saludable para su supervivencia. Este escenario se ha hecho cada vez más frecuente, razón por la cual la comunidad internacional se ha preocupado especialmente por estas personas.

Algunos desplazamientos ambientales se producen de forma temporal, mientras que las circunstancias que los originaron son provisionales. Sin embargo, hay personas que se ven obligadas a emigrar permanentemente de su país, ya que las causas que las han llevado a ello son irreversibles, como en los casos en que hay una destrucción significativa de la infraestructura del país, que difícilmente será reconstruida, o cuando hay un aumento en el nivel de los océanos, lo que hace imposible que las personas permanezcan en el país afectado.

Aquellos que migran debido a desastres ambientales no son reconocidos como refugiados. Este hecho ocurre por dos razones. En primer lugar, porque los instrumentos normativos que regulan el refugio exigen que el individuo sea perseguido y, en segundo lugar, por la ausencia de una norma que regule expresamente este tipo de desplazamiento. Por esta razón, la cuestión sigue careciendo, hasta el día de hoy, de una tutela más amplia, más objetiva y eficaz.

El Programa de las Naciones Unidas para el Medio Ambiente (PNUMA) define a los refugiados ambientales como:

Un grupo de personas que se han visto obligadas a abandonar sus hogares, temporal o permanentemente, debido a un deterioro visible de las condiciones ambientales (por razones naturales o humanas), lo que hace imposible su subsistencia o las pone en peligro, ya que estarían expuestas a graves violaciones de los derechos humanos.

Tal y como se extrae del concepto transcrito anteriormente, la definición es clara al afirmar que estos individuos están expuestos a graves violaciones de los derechos humanos, lo cual, de hecho, ocurre dentro de este escenario. Por lo tanto, entendemos la configuración de la violación de los derechos humanos de las personas desplazadas para que se les conceda el estatuto de refugiados.

Sin embargo, aunque la violación de los derechos humanos sigue siendo patente, los instrumentos normativos que regulan el refugio, ya sea a nivel global, regional, así como en el derecho interno brasileño, no 
reconocen que estos desplazados ambientales son refugiados, he aquí, según el entendimiento mayoritario, donde falta el elemento principal que caracteriza al refugio, en particular, la persecución.

Así es como estas personas permanecen legalmente desprotegidas incluso después de haber cruzado la frontera de su país, que ha sido completamente destruida por un desastre ambiental, de modo que no pueden permanecer en ella, y no hay condiciones dignas de supervivencia. La vulnerabilidad de estas personas, que necesitan una protección efectiva por parte del Estado (DEL MASSO; MIRANDA GONÇALVES; FERREIRA, 2015) que las recibe, sigue siendo clara, por lo tanto, jurídicamente desprotegida.

El hecho de que no se reconozca a las personas desplazadas por razones medioambientales como típicamente refugiados se debe a la ausencia de un requisito esencial, a saber, la persecución. Así, los individuos y grupos que cruzan fronteras, buscando hospitalidad y hospitalidad en otro estado de la sociedad internacional debido a problemas ambientales, se encuentran dentro de un limbo legal, un vacío legal, ya que no están cubiertos por la Convención sobre el Estatuto de los Refugiados de 51 y ningún otro instrumento regulador que regule el tema (PEREIRA, 2017).

Para una mejor comprensión del tema, presentaremos, en los siguientes tópicos, un esquema detallado del instituto jurídico del refugio, a fin de abordar sus matices y, especialmente, las normas que lo regulan a nivel global, regional y doméstico, especialmente para demostrar el concepto inicial, así como su expansión.

\section{DESPLAZAMIENTO FORZADO DE PERSONAS EN TODO EL MUNDO Y EL INSTITUTO LEGAL DEL REFUGIO}

Hay varios factores que llevan a las personas a emigrar a otro país. Algunas veces esta dislocación ocurre debido a sus propias voluntades. Otras veces, este cambio se presenta como necesario para la propia supervivencia. Algunos salen en busca de trabajo, mejores condiciones de vida, otros en busca de protección por diversas razones, en particular, por la violencia generalizada, los conflictos armados, el colapso de la gobernanza en sus países, los matrimonios forzados, las tensiones étnicas y sectarias, el reclutamiento forzado de soldados, la ocurrencia de desastres ambientales, la persecución dentro de su país (MAHLKE, 2017) etc.

Para aquellos que abandonan su país y cruzan la frontera para escapar 
de la persecución, el estatuto legal de refugiado está garantizado por la Convención de 51 sobre el Estatuto de los Refugiados.

Sin embargo, incluso antes de que el refugio fuera reconocido como un instituto legal apropiado, ya existía desde tiempos bíblicos, mientras que ya se contaban historias de personas que se vieron obligadas a abandonar su país como resultado de la persecución, por lo que buscaron refugio en un lugar seguro. En este sentido, José Henrique Fischel de Andrade hace hincapié en ello:

Desde los tiempos más remotos, el hombre ha vivido con el hecho de tener que dejar su plaga de origen porque ha disgustado a sus gobernantes, $o$ a la sociedad en la que vive. La infracción cometida lleva, como castigo por parte del que detenta el poder, a la suspensión de la acogida del malhechor que, en consecuencia, debe buscar la protección perdida en otro lugar (ANDRADE, 1996, p. 8).

En el mismo sentido, Andrea María Calazans Pacheco Pacific añade que "La Biblia recuerda la historia de la Sagrada Familia (José, María y el Niño Jesús) que se vio obligada a abandonar su tierra y refugiarse en Egipto para escapar de Herodes" (PACIFIC, 2010, p. 39).

A partir de ahí, se puede ver que el refugio ha acompañado a la humanidad desde el principio, aunque sea de manera discreta. Sin embargo, con el paso de los años, ha crecido en tamaño, tomando un nuevo formato a medida que la comunidad evoluciona latu sensu.

Este tema surge de manera significativa, asumiendo un nuevo paradigma, por así decirlo, a partir de la década de 1920, debido al final de la Primera Guerra Mundial, intensificándose con el surgimiento de la Segunda Guerra Mundial, con el consiguiente desplazamiento forzado masivo de personas en Europa.

Este intenso movimiento despertó en la comunidad internacional la preocupación por estas personas y, a partir de entonces, nació la necesidad de conceder protección jurídica a este grupo minoritario de individuos, llamados refugiados.

Es importante señalar que el refugio ya existía antes de su reconocimiento normativo. En ese sentido:

Se puede decir que la protección de los refugiados, de manera coordinada, se inició a través de las actividades de la Liga de las Naciones. Esto se debió principalmente a los acontecimientos que tuvieron lugar poco antes, durante y sobre todo inmediatamente después de la primera gran guerra (ANDRADE, 1996, p. 20).

La Sociedad de Naciones es una organización internacional creada por el Tratado de Versalles en 1919, con la premisa principal de asegurar 
la paz en el mundo. También es responsable de supervisar los comités establecidos para tratar las cuestiones internacionales pertinentes.

A pesar de que el Pacto de la Sociedad de las Naciones de 1920 no mencionaba expresamente la protección de los refugiados, la realidad en la que vivían los países europeos en ese momento, especialmente en lo que respecta a los desplazamientos masivos resultantes de las persecuciones provocadas por el final de la Primera Guerra Mundial, suscitó preocupación en la comunidad internacional, que, a través de la Sociedad de las Naciones, creó la Comisión de Refugiados, que se ocuparía de las cuestiones específicas de esas personas, en particular a través del Comité de Refugiados, encabezado por el Sr. Fridtjof Nansen, primer Alto Comisionado de la Sociedad de las Naciones para los Refugiado.

La protección dada a los refugiados en este período fue de naturaleza legal y no humanitaria, y el refugio fue visto como algo transitorio, que surgió naturalmente con motivo del final de la Primera Guerra Mundial. Sin embargo, con el tiempo se convirtió en algo cada vez más común, mientras que "[...] los grupos de personas que buscaban protección crecieron, y la preocupación por sus destinos comenzó a ser objeto de discusión en la Sociedad de Naciones" (ANDRADE, 1996, p. 23).

En este contexto, se destaca la importancia de la Sociedad de las Naciones en el contexto histórico de la protección jurídica de los refugiados, porque fue a partir de las preocupaciones y acciones de esta organización internacional que surgió en el derecho internacional la preocupación y la necesidad urgente de proteger a estas minorías.

Sin embargo, debido a la aparición de nuevos conflictos, especialmente con el estallido de la Segunda Guerra Mundial, la Liga de las Naciones se disolvió y, para asumir sus funciones, se creó la Organización de las Naciones Unidas (ONU) en 1945. En su primer período de sesiones, se presentó a la Asamblea General la preocupación y la necesidad de crear un nuevo órgano dedicado exclusivamente a la cuestión de los refugiados.

Antes de que se aprobara la Declaración Universal de los Derechos Humanos el 15 de diciembre de 1946, la Asamblea General de la ONU aprobó la creación de la Organización Internacional de Refugiados (OIR), con carácter provisional. Las principales tareas de la OIR eran de:

[...] identificar a los refugiados, expedir su documentación, ayudarles en sus necesidades, responder a sus solicitudes de repatriación, ayudarles en su integración local y, cuando fuese necesario, intervenir para obtener su reasentamiento en un tercer país ${ }^{3}$ (SANTIAGO, 2003, p. 86).

3 Traducción de los autores. 
Cabe mencionar, sin embargo, que incluso antes de que finalizara el mandato de la OIR, la Asamblea General de las Naciones Unidas ya estaba debatiendo quién asumiría su sucesión, mientras que para hacer frente de manera efectiva a las dificultades derivadas del creciente número de refugiados era necesario adoptar criterios universalmente aceptados.

Es por esta preocupación que la Declaración Universal de Derechos Humanos del 10 de diciembre de 1948, proclamada en su artículo 14, que "[...] toda persona, víctima de persecución, tiene derecho a buscar y disfrutar del asilo en otros países". Un año después, el 3 de diciembre de 1949, la Asamblea General de la ONU creó el Alto Comisionado de las Naciones Unidas para los Refugiados (ACNUR), confiriéndole la función exclusiva de brindar protección a estas personas.

Al inicio de sus actividades, ACNUR tenía una concepción innovadora del refugio, que le daba un carácter humanitario y apolítico. Con este espíritu, y en un intento de comprender a fondo este instituto, incluso para una acción más eficaz, pidió a un profesor del "Centre d'Études de Politique Etrangère" de París, el profesor Jacques Vernant, que hiciera un estudio sobre el tema de los refugiados. Este estudio destaco que:

[...] los problemas de los refugiados en general, no limitados a los que están bajo la protección de ACNUR, son problemas profundos, lo que concluye que el mayor mal de la crisis de los refugiados es su carácter repetitivo y permanente ${ }^{4}$ (SANTIAGO, 2003, p. 88).

Ante este estudio en profundidad, se puso de relieve la necesidad de prestar mayor atención a la institución del refugio, sobre todo por la realidad que se vivía en ese momento. Fue entonces cuando la Asamblea General de la ONU, el 26 de julio de 1951, aprobó la Convención sobre el Estatuto de los Refugiados, considerada por la ONU como la Carta Magna de este instituto legal.

\subsection{Estatuto de Refugiados de 1951 y su Protocolo de 1967}

La Convención de 1951, también conocida como la Convención de 1951 sobre el Estatuto de los Refugiados, el Estatuto de los Refugiados y la Convención de Ginebra de 1951, fue discutida y desarrollada durante una conferencia de plenipotenciarios en Ginebra en julio de 1951.

Dado que esta conferencia tuvo lugar fuera de la estructura de la ONU, otros países que no formaban parte de esta organización, pero que estaban

4 Traducción de los autores. 
interesados en este tema, pudieron participar en la redacción de su texto, que utilizó como referencia inicial el propio estatuto del ACNUR. Aunque la Convención fue finalizada en julio de 1951, no entró en vigor hasta 1954 (ANDRADE, 2010).

Mientras se discutían las cuestiones que debía abarcar la Convención, se observaron diferencias entre los países participantes. En primer lugar, con respecto a la competencia ratione temporis de la Convención de 51, dado que algunos países argumentaron que la definición de refugiado debería ser amplia, sin límite de tiempo. Otros, por otra parte, querían establecer un plazo para el reconocimiento de un refugiado. Al final, el texto normativo adoptó el plazo, bajo la justificación de que permite a los Estados medir el alcance de sus obligaciones.

Otra divergencia importante se produce en relación con el límite geográfico, dado que, por una parte, algunos Estados pretenden que la Convención de 51 pueda aplicarse a cualquier refugiado en el mundo y, por otra, los Estados entienden que este instrumento sólo debe aplicarse a los refugiados europeos, que son los más necesitados de protección. Esta última posición fue la que se incorporó al texto de la Convención.

Por lo tanto, al final de la Conferencia de Plenipotenciarios, el texto completo de la Convención de 51 se deriva de ella, que presenta en su primer artículo, el concepto de refugiado, que es todo aquel que:

[...] debido a los acontecimientos que tuvieron lugar antes del 1 de enero de 1951 en Europa y a un temor fundado de persecución por motivos de raza, religión, nacionalidad, grupo social u opinión política, se encuentra fuera del país de su nacionalidad y no puede o, debido a ese temor, no desea acogerse a la protección de ese país; o porque no tiene nacionalidad y se encuentra fuera del país de su residencia habitual, como consecuencia de esos acontecimientos, no puede o, a causa de tales temores, no desea regresar a él (ONU, 1951).

A la luz de este concepto introducido por la Convención de 51, parece que este instrumento:

[...] estableció una limitación temporal y geográfica, ya que la condición de refugiado se limitaba a los acontecimientos ocurridos antes del 1 de enero de 1951 en el continente europeo. Esto significa que los refugiados sólo fueron reconocidos como tales si eran el resultado de episodios ocurridos antes del 1 de enero de 1951. Aunque se aplica a miles de personas - desde los años cincuenta la mayoría de los refugiados eran europeos -, esta definición ha resultado ineficaz con el paso del tiempo (PIOVESAN, 2003, p. 119). 
El desplazamiento masivo no se limitó a los europeos, mientras que en muchos otros países del mundo este fenómeno se repitió, quizás con la misma intensidad. Las personas que se ven obligadas a abandonar su país por las mismas razones que las establecidas en el artículo 1 de la Convención de 51, quedan desprotegidas porque no están amparadas por el Estatuto de los Refugiados debido a la limitación territorial y temporal.

Ante esta situación, la comunidad internacional se dio cuenta de la necesidad de llenar este vacío, ampliando el alcance de la definición de refugiado, por lo que el 31 de enero de 1967 se publicó el Protocolo sobre el Estatuto de los Refugiados, que en su artículo 1 renuncia a las delimitaciones territoriales y temporales que habían existido hasta entonces.

Así, a partir de la elaboración del Protocolo de 67, en particular según lo dispuesto en su artículo 1, párrafo 2, se convirtieron en refugiados no sólo de los europeos afectados por los acontecimientos ocurridos antes del 1 de enero de 1951, sino cualquier persona en el mundo que, debido a un temor fundado de persecución por motivos de raza, religión, nacionalidad, grupo social u opiniones políticas, se encontrara fuera del país de su nacionalidad, y que no pudiera o, debido a ese temor, no quisiera acogerse a la protección de ese país; o que, por carecer de nacionalidad y encontrarse fuera del país de su residencia habitual, como consecuencia de tales acontecimientos, no pueda o, debido a tales temores, no desee regresar a él (ONU, 1967).

En principio, para que un individuo sea reconocido como refugiado, deben existir dos requisitos que son interdependientes: la extraterritorialidad y un temor fundado a ser perseguido por motivos de raza, religión, nacionalidad, grupo social u opinión política.

Se observa que el refugiado no es un extranjero ordinario, por así decirlo, sino un extranjero que está en riesgo dentro de su propio país (FOSTER, 2014) y que, por lo tanto, se ve obligado a abandonarlo.

Es evidente que la Convención del 51 y el Protocolo del 67, aunque regulan la misma materia, son documentos independientes y distintos, y este último, como se ha visto, fue creado para eliminar del texto original el límite temporal y territorial previamente establecido, extendiendo el concepto de refugiado a los no europeos. Cabe señalar que es perfectamente posible que los Estados se adhieran a uno solo de ellos, lo que no los obliga frente al otro no ratificado, pero también es posible que se adhieran a ambos.

La Convención de 51 y el Protocolo de 67 son instrumentos de protección global que ocupan la cima de la pirámide del instituto jurídico 
del refugio, mientras que el contenido de sus textos se utilizó como parámetro para la concepción de otros documentos posteriores que regulan el refugio tanto a nivel regional, como la Convención de la Organización de la Unidad Africana de 1969 y la Declaración de Cartagena sobre los Refugiados de 1984, como a nivel interno de los Estados, como la ley brasileña 9.474/97 (Estatuto de los Refugiados).

\subsection{Convención de la Organización de la Unidad Africana (OUA) de 1969 y la Declaración de Cartagena sobre los Refugiados de 1984}

El concepto inicial de refugiado, ampliado posteriormente por el Protocolo de 67, con la consiguiente ruptura de la limitación territorial y temporal, sigue siendo insuficiente para satisfacer la creciente y generalizada demanda de personas que se ven obligadas a abandonar su país, por diversas razones, pero no menos importante que las expuestas en el Estatuto del Refugiado de 51 y su Protocolo.

No existía una estructura de protección capaz de acoger a este grupo de personas que, aunque se encontraban en un estado de peligro latente, se encontraban completamente desprotegidas debido a una laguna legal, por así decirlo, que las mantenía excluidas de la categoría de refugiados.

Frente a esta realidad, los países africanos que sufrían el intenso flujo de desplazamientos forzados debido a las guerras civiles causadas por el proceso de descolonización y la consiguiente independencia de estos Estados se vieron obligados a crear un documento regional que pudiera extender el concepto de refugiados a personas que no estaban cubiertas por la Convención de 1951 y su Protocolo de 1967.

Fue entonces cuando, con el fin de salvaguardar a estos desplazados atípicos, se firmó la Convención de la Organización de la Unidad Africana en 1969 en Addis Abeba, que fue editada para regular los aspectos específicos de los problemas de los refugiados en África.

Este documento regional africano aportó una importante innovación al marco jurídico para la protección de los refugiados, al tiempo que ampliaba su concepto original al ampliar su aplicabilidad en el Artículo 1, II:

$[\ldots]$ a toda persona que, como consecuencia de una agresión, una ocupación externa, una dominación extranjera o de acontecimientos que perturben gravemente el orden público en la totalidad o en parte de su país de origen o del país del que sea nacional, esté obligada a abandonar su lugar de residencia habitual para buscar refugio en otro lugar que no sea su país de origen o su nacionalidad. 
La importancia de esta Convención se refiere también al grado de preocupación por los desplazados internos, "[...] el Tratado regional de la Unión Africana es hasta ahora la única prueba de la preparación para dar una posición jurídica legítima a la protección de las poblaciones desplazadas internamente" ${ }^{\text {. }}$.

Años más tarde, otro intenso flujo migratorio de personas tuvo lugar en el continente americano, debido a los conflictos armados en Centroamérica causados por guerrilleros que querían derrocar las dictaduras militares.

Con el fin de resolver este problema, en 1984 se celebró en Cartagena de Indias una reunión entre países latinoamericanos, oportunidad que puso de relieve la necesidad de crear un documento similar al publicado por la OUA y que pudiera satisfacer la demanda de refugiados en América.

Esta reunión dio lugar al texto de la Declaración de Cartagena de 1984, instrumento de protección regional de los refugiados que, además de proclamar los mecanismos y estrategias necesarios para hacer frente al problema del desplazamiento forzado, y siguiendo el mismo espíritu que la Declaración Africana, amplió el concepto de este instituto. Por lo tanto, la Tercera Conclusión de esa Declaración contiene lo siguiente:

[...] También se consideran refugiados a las personas que han huido de sus países porque su vida, su seguridad o su libertad se han visto amenazadas por la violencia generalizada, las agresiones extranjeras, los conflictos internos, las violaciones masivas de los derechos humanos u otras circunstancias que han perturbado gravemente el orden público.

Cabe señalar, sin embargo, que:

[...] la definición ampliada y la definición clásica de refugiado no deben considerarse excluyentes e incompatibles, sino, por el contrario, complementarias. El concepto de refugiado, tal como se define en la Convención y el Protocolo, proporciona una base jurídica adecuada para la protección universal de los refugiados.

Así, como columna vertebral de este instituto, deriva de los instrumentos globales de protección, ramificaciones capaces de ampliar el concepto rudimentario de refugiado, permitiendo, entonces, el uso técnico-jurídico de todos estos instrumentos concomitantemente, como una forma de protección integral de estas personas.

No se puede negar que la ampliación del concepto de refugiado por estos dos instrumentos regionales representa un avance significativo en el campo de la protección de estas personas. Sin embargo, dado que no son documentos globales, la aplicabilidad por otros Estados es opcional. Así,

5 Traducción hecha por los autores. 
otros Estados obligados no son compelidos a admitir refugiados en sus países debido a la ampliación del concepto que traen consigo la Convención Africana de 69 y la Declaración de Cartagena de 84. En ese sentido:

El único problema con la ampliación del concepto de refugiado por parte de algunos Estados es la falta de uniformidad en la definición, de modo que los refugiados reconocidos como tales en la OUA o en la Declaración de Cartagena (1984) no se consideran cubiertos por la protección de los refugiados en otros Estados, lo que impide la aplicación de criterios homogéneos en todo el mundo, lo que permitiría la creación de un sistema verdaderamente universal, lo que obstaculizaría la labor de ACNUR.

Aun así, ambos documentos merecen ser celebrados, pues además de representar un avance en esta materia, son reconocidos como precedentes protectores del refugio, sirviendo de referencia para otros Estados, como Brasil, que adoptó en su ordenamiento jurídico interno el concepto ampliado de refugiado.

\section{ESTANDARIZACIÓN DEL REFUGIO EN BRASIL: ESTATUTO DE LOS REFUGIADOS}

La Ley 9474/97 es la norma que regula el refugio en el sistema jurídico brasileño. Es responsable de gobernar todo el marco de este instituto, siendo considerado tanto por las Naciones Unidas (ONU) como por los estudiosos del tema, como una de las leyes más modernas, vanguardistas e integrales del mundo en materia.

Según Liliana Lyra Jubilut:

Resulta que la mayoría de estas leyes tratan el tema de los refugiados bajo la ley de inmigración o asilo, por ejemplo, en los Estados Unidos y Japón, y no existe una ley específica. La relevancia de la legislación nacional brasileña reside en la elaboración de ésta, ya que este hecho permite una mejor adaptación del texto legal a las necesidades de los refugiados (JUBILUT, 2007, p. 191).

En palabras de Valerio de Oliveira Mazzuoli "[...] esta norma es la primera en aplicar un tratado de derechos humanos en Brasil, y sigue siendo la ley latinoamericana más amplia que existe para abordar el tema" (MAZZZUOLI, 2016, p. 351). Sin embargo, aunque se considera como tal, todavía es poco conocida, incluso por los propios refugiados y solicitantes de asilo.

Esta ley fue sancionada en Brasil el 22 de julio de 1997, por el entonces presidente Fernando Henrique Cardoso, y editada con el objetivo 
de definir mecanismos capaces de incorporar todo el texto normativo de la Convención de 1951 y el Protocolo de 1967 al sistema jurídico brasileño.

Sin embargo, la ley de refugio en Brasil no se limitó a adoptar únicamente el contenido jurídico de los textos relacionados con los refugiados a nivel mundial, sino que incorporó al cuerpo de la norma las innovaciones reflejadas en la Declaración de Cartagena sobre los Refugiados de 1984, que amplió el concepto de refugiados.

Cabe destacar que la Ley 9.474/97 es bastante completa e inequívoca, por lo que, a través de una simple lectura, es posible comprender su contenido. Por lo tanto, no es necesario realizar un análisis exhaustivo e individualizado de cada uno de sus artículos, por lo que sólo se destacarán los puntos más relevantes, empezando por el concepto de refugiado que aporta. El artículo 1 dispone que:

Art. $1^{\circ}$ Será reconocido como refugiado todo individuo que:

I - debido a fundados temores de persecución por motivos de raza, religión, nacionalidad, grupo social u opiniones políticas se encuentre fuera de su país de nacionalidad y no pueda o no quiera acogerse a la protección de tal país;

II - no teniendo nacionalidad y estando fuera del país donde antes tuvo su residencia habitual, no pueda o no quiera regresar a él, en función de las circunstancias descritas en el inciso anterior;

III - debido a grave y generalizada violación de derechos humanos, es obligado a dejar su país de nacionalidad para buscar refugio en otro país.

Por lo tanto, son requisitos esenciales para el reconocimiento de un refugio: (a) un temor fundado a la persecución; (b) la condición de extraterritorialidad; y finalmente, y de manera innovadora, (c) debido a una violación grave y generalizada de los derechos humanos.

Cabe señalar que la legislación brasileña, al igual que la Declaración de Cartagena de 1984, adoptó el concepto ampliado de refugiado, permitiendo al mismo tiempo la concesión de refugio a quienes, debido a violaciones graves y generalizadas de los derechos humanos, se ven obligados a abandonar su país de nacionalidad en busca de refugio en otro país.

Dentro de esta perspectiva, es necesario reconocer que el individuo que abandona su país por haber sido afectado por un desastre ambiental, obviamente estaba sufriendo violaciones a sus derechos humanos. Como se mencionó exhaustivamente, los desastres ambientales que destruyen la infraestructura de un país limitan el disfrute del acceso a la salud ${ }^{6}$, la educación ${ }^{7}$ y una vivienda digna, es decir, hacen imposible que las personas

6 Gonçalves (2017).

7 Gonçalves (2018). 
afectadas por este desastre puedan disfrutar de sus derechos básicos.

Por ello, es imperativo conceder a estas personas el beneficio del refugio, ya que presenta el requisito legal de una violación grave y generalizada de los derechos humanos, cuya expansión del concepto de refugiado se ha ampliado en el texto de la ley. Por lo tanto, no hay duda de que las personas desplazadas por problemas ambientales deben ser reconocidas en Brasil como refugiados típicos.

Sin embargo, por el contrario, Brasil, de manera equivocada, no ha reconocido como refugiados a las víctimas del desastre ambiental que buscan refugio aquí. Tomemos como ejemplo el caso de los haitianos que se vieron obligados a abandonar su país, devastado por un terremoto, lo que les impidió permanecer en ese estado debido a graves y generalizadas violaciones de los derechos humanos.

Para atender esta demanda, el Consejo Nacional de Migración emitió la Resolución Normativa 97/2012, que regula la concesión de un visado permanente a estas personas por razones humanitarias, el "visado humanitario". Sin embargo, creemos que no era lo correcto, ya que nuestro sistema jurídico cuenta con una legislación específica capaz de proteger esta situación de forma más eficaz. Lo correcto sería reconocerlos como refugiados, y sería totalmente innecesario crear un subterfugio normativo.

En vista de ello, es evidente que la legislación brasileña no ha hecho nada para adoptar el concepto ampliado de refugiado si el texto de la ley no se aplica al caso propuesto, de modo que el concepto queda vacío de eficacia, al ser letra muerta, mientras que existe, pero no se aplica.

\section{CONCLUSIÓN}

De todo este trabajo de investigación, puede concluir que existe una clara necesidad de ampliar el concepto de refugiado establecido por la Convención de 51 y su Protocolo Adicional, mientras que estos instrumentos normativos no han seguido el ritmo de los cambios en el mundo, y han terminado siendo insuficientes en su función protectora. Esto se debe a que, en la actualidad, las razones que llevan a una persona a abandonar su país en busca de protección en otro lugar no se limitan al criterio de la persecución, y es sumamente importante reconocer que uno de los principales factores que causan el desplazamiento de personas en la actualidad proviene de la ocurrencia de desastres ambientales. 
En este sentido, es convincente reconocer que las personas que se ven obligadas a abandonar su país de origen como consecuencia de desastres ambientales deben ser reconocidas como refugiados en virtud de la Convención de 1951 y, en consecuencia, se les debe conceder toda la protección debida.

Esta protección se debe principalmente al hecho de que una región afectada por un desastre ambiental, que causó la destrucción de toda la infraestructura, como el colapso de hospitales, escuelas, puestos de salud, indudablemente causa el efecto directo de la prestación de servicios básicos dentro de la sociedad, con el fin de perjudicar incluso la condición de vivir dignamente en este contexto.

Si no hay salud, educación, alimentos, agua tratada, vivienda o higiene, se hace difícil sobrevivir con la mínima dignidad en ese lugar. No hay duda de que los derechos más mundanos de estos seres humanos serán violados y, por esta razón, es necesario reconocer la necesidad de otorgar protección a estas personas, independientemente de que se ajusten o no a lo que preceptúa la norma.

En nuestra opinión, cuando se agrava una condición de vida, las violaciones de los derechos humanos son el resultado natural de ello. Lógicamente, cuando todo un país se ve afectado por un desastre ambiental que ha causado miles de muertes, destrucción de infraestructura básica, alcanzando su funcionamiento normal, causando por extensión daños y pérdidas a la sociedad en su conjunto, especialmente al desarrollo humano, estamos diciendo que este desastre ambiental causa a los indígenas una grave y generalizada violación de sus derechos, haciéndolos vulnerables y desprovistos de protección efectiva.

Así es como el Estado no puede, con excesiva formalidad, aferrarse sólo al texto de la ley en detrimento de algo mucho más grande. En este caso, lo que hay que tener en cuenta, sobre todo porque se trata de cuestiones de derechos humanos, es la observancia irrestricta del principio pro homine, a fin de garantizar a las víctimas de un desastre ambiental una protección a gran y amplia escala.

Lo que estamos tratando de probar es que, si se produce una violación patente de los derechos humanos como consecuencia de una catástrofe medioambiental, hay que garantizar a las víctimas de este fenómeno la mayor protección posible, es decir, que se les conceda el status de refugiado y no sólo un visado humanitario, con el fin de tratar el refugio de un instituto mucho más poderoso, capaz de proteger de forma más eficaz a 
los que se benefician de él.

En Brasil, la legislación que regula el instituto del refugio, en particular la ley 9.474/97, adopta el concepto ampliado de refugiado, al tiempo que reconoce al individuo que se ve obligado a abandonar su país de nacionalidad para buscar refugio en otro país debido a una violación grave y generalizada de los derechos humanos, como refugiado. En este sentido, Brasil debe reconocer a las personas que se trasladan aquí debido a la ocurrencia de un desastre ambiental en su país de origen como refugiados. Esto se debe a que su desplazamiento se debió también a la violación de los derechos humanos resultante de un desastre ambiental, es decir, que el caso en cuestión se adapta perfectamente al tipo legal, por lo que debería haber un reconocimiento de estas personas como refugiados.

Por lo tanto, lo que concluimos es que, dada la situación de emergencia y relevancia en la que se encuentran estas personas, la falta de definición del término y el vacío normativo de protección específica en los documentos de protección global, es convincente ampliar el concepto de refugiado o, alternativamente, promulgar una ley específica capaz de otorgar a este grupo de migrantes, un conjunto de derechos y garantías, capaces de llevarles el mínimo de dignidad, ya que han sido perseguidos por un problema que no es sólo de ellos, sino también de responsabilidad global, sobre todo debido a que parte de este problema se debe a la ausencia de un desarrollo sostenible de la humanidad

\section{REFERENCIAS}

ANDRADE, J. H. F. Direito internacional dos refugiados: evolução histórica. Rio de Janeiro: Renovar, 1996.

ANDRADE, J. H. F. Guerra Fria e refugiados: da gênese política do ACNUR e da Convenção de 1951. In: IKAWA, D.; PIOVESAN, F.; SARMENTO, D. Igualdade, diferença e direitos humanos. Rio de Janeiro: Lumen Juris, 2010. p. 771-807.

BECK, U. A metamorfose do mundo: como as alterações climáticas estão a transformar a sociedade. Lisboa: Edições 70, 2015.

CARVALHO, D. W. Dano ambiental futuro: a responsabilização civil pelo risco ambiental. Porto Alegre: Livraria do Advogado, 2013.

CARVALHO, D. W. Desastres ambientais e sua regulação jurídica: 
deveres de prevenção, resposta e compensação ambiental. São Paulo: Revista dos Tribunais, 2015.

CNI. Resolução Normativa n. 97, de 12 de janeiro de 2012. Disponible en: https://www.legisweb.com.br/legislacao/?id=116083. Acceso el: $17 \mathrm{de}$ abril de 2018.

COLÓQUIO SOBRE PROTEÇÃO INTERNACIONAL DOS REFUGIADOS NA AMÉRICA CENTRAL, MÉXICO E PANAMÁ. Declaração de Cartagena de 1984. Disponible en: http://www.acnur.org/ fileadmin/scripts/doc.php?file=fileadmin/Documentos/portugues/BD Legal/Instrumentos_Internacionais/Declaracao_de_Cartagena. Acceso el: 17 de abril de 2018.

DEL MASSO, F. D.; GONÇALVES, R. M.; FERREIRA, R. M. Z. A (re) invenção do Estado do século XXI: o regresso ao liberalismo como suporte do sistema democrático. Revista Internacional Consinter de Direito, v. I, 2015 .

FOSTER, M.; HATHAWAY, J. The law of refugee status. 2. ed. Cambridge: Cambridge University Press, 2014.

FREITAS, J. Sustentabilidade: direito ao futuro. Belo Horizonte: Fórum, 2016.

GONÇALVES, R. M. "La responsabilidad patrimonial de la Administración Pública en el ámbito sanitario español”. In: SOUSA, I. F. A. Direito à saúde: dilemas atuais. Curitiba: Juruá, 2017. p. 247-268.

GONÇALVES, R. M. El derecho a la educación como derecho humano: especial referencia a la jurisprudencia española actual. In: ANJOS, M. R. et al. Atualidades na ciência jurídica: intercâmbio iberoamericano. Maia: Instituto Politécnico da Maia, 2018. p. 11-21.

JUBILUT, L. L. O direito internacional dos refugiados e sua aplicação no ordenamento jurídico brasileiro. São Paulo: Método, 2007.

LIGA DAS NAÇÕES. Pacto da Liga das Nações de 1920. Disponible en: http://pfdc.pgr.mpf.mp. br/atuacao-e-conteudos-de-apoio/legislacao/ segurancapublica/PACTO_DA_SOCIEDADE_DAS_NACOES.pdf. Acceso el: 17 de abril de 2018.

MAHLKE, H. Direito internacional dos refugiados: novo paradigma jurídico. Belo Horizonte: Arraes, 2017. 
MAZZUOLI, V. O. Curso de direito internacional público. 10. ed. São Paulo: Revista dos Tribunais, 2016.

ONU - ORGANIZAÇÃO DAS NAÇÕES UNIDAS. Convenção Relativas aos Refugiados de 1951. Disponible en: http://www.acnur.org/t3/fileadmin/ Documentos/portugues/BDL/Convencao_relativa_ao_Estatuto_dos_ Refugiados.pdf. Acceso el: 17 de abril de 2018.

ONU - ORGANIZAÇÃO DAS NAÇÕES UNIDAS. Declaração Universal de Direitos Humanos de 10 de dezembro de 1948. Disponible en: http://www.ohchr.org/EN/UDHR/Documents/UDHR_Translations/ por.pdf. Acceso el: 20 de marzo de 2018.

ONU - ORGANIZAÇÃO DAS NAÇÕES UNIDAS. Protocolo de 1967 Relativo ao Estatuto dos Refugiados. Disponible en: http://www.acnur.org/ t3/fileadmin/Documentos/portugues/BDL/Protocolo_de_1967_Relativo_ ao_Estatuto_dos_Refugiados.pdf. Acceso el: 17 de abril de 2018.

OUA - ORGANIZAÇÃO DA UNIDADE AFRICANA. Convenção da Organização da Unidade Africana de 1969. Disponible en: http://www. adus.org.br/convencao-da-organizacao-de-unidade-africana/. Acceso el: 17 de abril de 2018.

PACÍFICO, A. M. C. P. O capital social dos refugiados: bagagem cultura e políticas públicas. Maceió: Edufal, 2010.

PEREIRA, L. D. D. A proteção internacional da pessoa humana, a hospitalidade e os deslocamentos forçados por mudanças climáticas e por desastres ambientais: opor vir no Direito Internacional dos Refugiados à luz do Direito Internacional para a Humanidade. Tese (Doutorado) Universidade Federal de Minas Gerais, Belo Horizonte, 2017.

PIOVESAN, F. Temas de direitos humanos. São Paulo: Max Limonad, 2003.

SANTIAGO, J. R. Derechos humanos, derecho de los refugiados: evolución y convergências. In: PEYTRIGNET, G.; SANTIAGO, J. R.; CANÇADO TRINDADE, A. A. (org.). Las tres vertientes de La protección internacional de los derechos de la persona humana. Ciudad de México: Porrúa, 2003. 
Artículo recibido en: 30/07/2019.

Artículo aceptado en: 20/12/2019.

\section{Cómo citar este artículo (ABNT):}

GONÇALVES, R. M.; SILVA, L. M. F. Desplazamientos forzados en el desarrollo de desastres ambientales: la violación de los derechos humanos como requisito previo para el reconocimiento del refugio ambiental en Brasil. Veredas do Direito, Belo Horizonte, v. 17, n. 37, p. 11-34, ene.-abr. 2020. Disponible en: http://revista.domhelder.edu.br/index.php/veredas/ article/view/1606. Acceso el: día de mes de año. 